\title{
INDEPENDENT VERIFICATION SURVEY REPORT FOR THE LONG ISLAND SOLAR FARM BROOKHAVEN NATIONAL LABORATORY UPTON, NEW YORK
}

\author{
E. M. Harpenau
}

Prepared for the

U.S. Department of Energy

\section{O R I S E}


The Oak Ridge Institute for Science and Education (ORISE) is a U.S. Department of Energy facility focusing on scientific initiatives to research health risks from occupational hazards, assess environmental cleanup, respond to radiation medical emergencies, support national security and emergency preparedness, and educate the next generation of scientists. ORISE is managed by Oak Ridge Associated Universities. Established in 1946, ORAU is a consortium of 98 colleges and universities.

\section{NOTICES}

The opinions expressed herein do not necessarily reflect the opinions of the sponsoring institutions of Oak Ridge Associated Universities.

This report was prepared as an account of work sponsored by the United States Government. Neither the United States Government nor the U.S. Department of Energy, nor any of their employees, makes any warranty, expressed or implied, or assumes any legal liability or responsibility for the accuracy, completeness, or usefulness of any information, apparatus, product, or process disclosed, or represents that its use would not infringe on privately owned rights. Reference herein to any specific commercial product, process, or service by trade name, mark, manufacturer, or otherwise, does not necessarily constitute or imply its endorsement or recommendation, or favor by the U.S. Government or any agency thereof. The views and opinions of authors expressed herein do not necessarily state or reflect those of the U.S. Government or any agency thereof. 


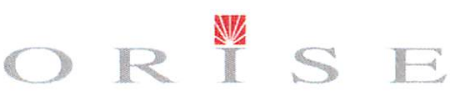

\section{INDEPENDENT VERIFICATION SURVEY REPORT FOR THE LONG ISLAND SOLAR FARM BROOKHAVEN NATIONAL LABORATORY UPTON, NEW YORK}

Prepared by:

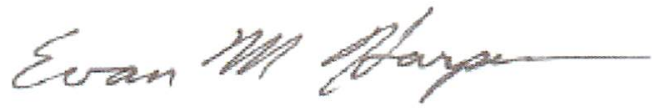

E. M. Harpenau, Assistant Project Manager

Independent Environmental Assessment and Verification

Reviewed by:

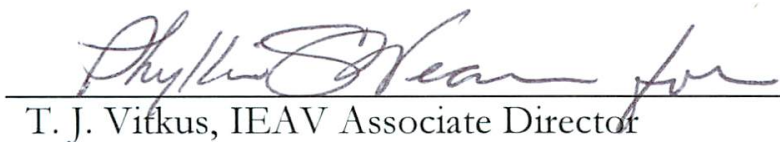

Director Survey Operations

Independent Environmental Assessment and Verification

Reviewed by:

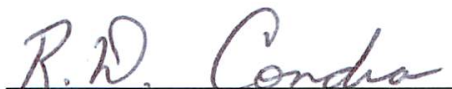

Reviewed by: $\begin{aligned} & \text { R. D. Condra, Laboratory Group Manager } \\ & \text { Independent Environmental Assessment and Verification }\end{aligned}$

Reviewed by: $\begin{aligned} & \text { R. D. Condra, Laboratory Group Manager } \\ & \text { Independent Environmental Assessment and Verification }\end{aligned}$

Date:

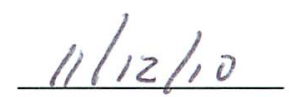

Date: $11 / 12 / 10$

Date: $1 / 12 / 10$

Independent Environmental Assessment and Verification

Date: $11 / 15 / 10$ 


\title{
INDEPENDENT VERIFICATION SURVEY REPORT FOR THE LONG ISLAND SOLAR FARM BROOKHAVEN NATIONAL LABORATORY UPTON, NEW YORK
}

\author{
Prepared by \\ E. M. Harpenau

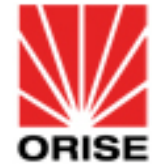 \\ Independent Environmental Assessment and Verification Program \\ Oak Ridge Institute for Science and Education \\ Oak Ridge, Tennessee 37831-0017 \\ Prepared for the \\ U.S. Department of Energy
}

FINAL REPORT

NOVEMBER 2010

This report is based on work performed by the Oak Ridge Institute for Science and Education Under contract number DE-AC05-06OR23100 with the U.S. Department of Energy. 


\section{ACKNOWLEDGMENTS}

The author would like to acknowledge the significant contributions of the following staff members:

\section{FIELD AND SUPPORT}

E. M. Harpenau

T. D. Herrera

E. Montalvo

\section{LABORATORY}

R. D. Condra

J. S. Cox

W. P. Ivey

W. F. Smith

\section{ADMINISTRATIVE}

J. L. Clary

R. M. Fink

K. M. Moore

S. J. Orns

A. Ramsey

F. G. Riva

EDITORIAL

D. J. Steger

\section{ILLUSTRATORS}

A. M. Hood 


\section{TABLE OF CONTENTS}

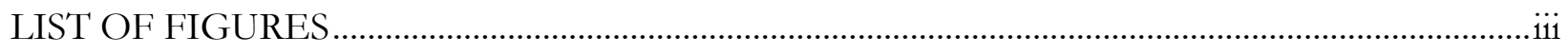

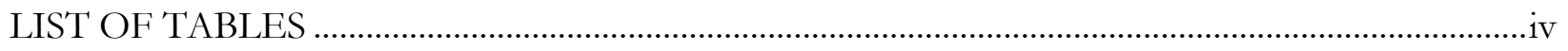

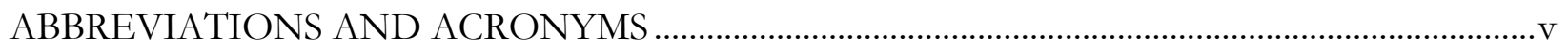

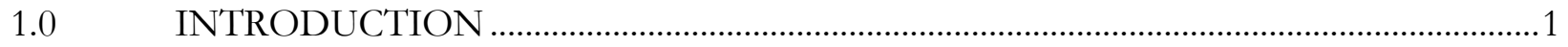

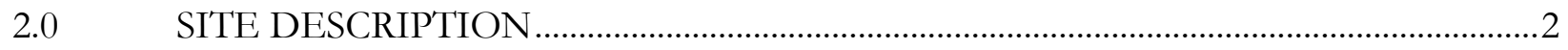

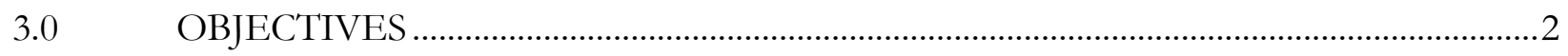

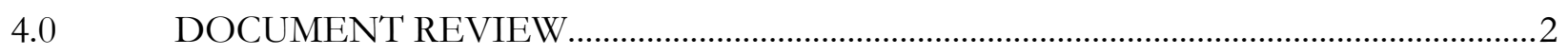

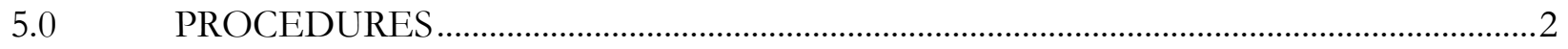

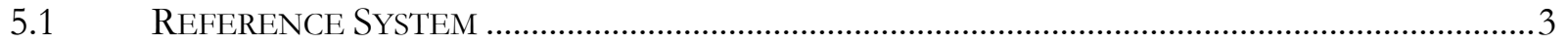

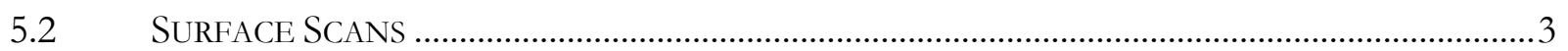

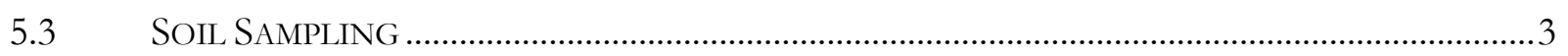

6.0 SAMPLE ANALYSIS AND DATA INTERPRETATION

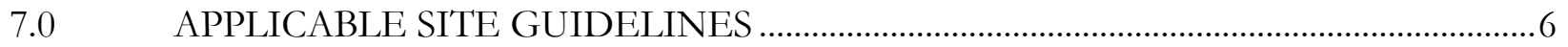

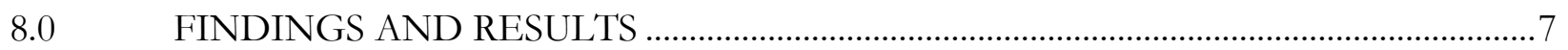

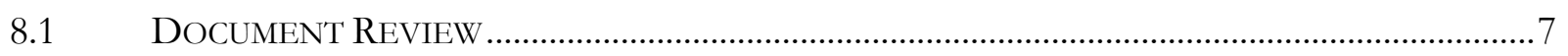

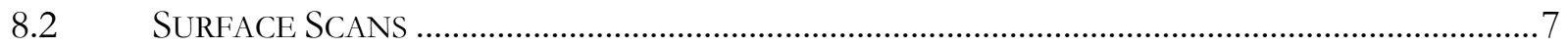

8.3 RADIONUCLIDE CONCENTRATIONS IN SOIL AND RoOF SAMPLES........................................

9.0 COMPARISON OF RESULTS WITH GUIDELINES ...................................................

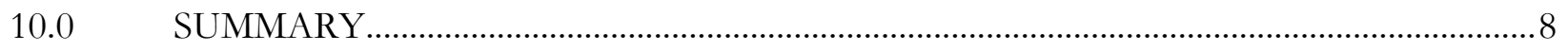

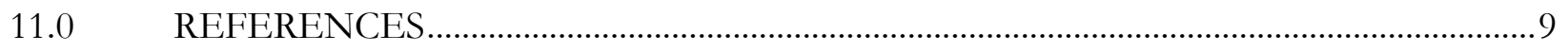

APPENDIX A FIGURES

APPENDIX B TABLES

APPENDIX C MAJOR INSTRUMENTATION

C.1 SCANning AND MEASUREMEnt Instrument/DeteCtor Combinations ................. C-1

C.2 LABORATORY ANALYTICAL INSTRUMENTATION........................................................................ C-1 APPENDIX D SURVEY AND ANALYTICAL PROCEDURES

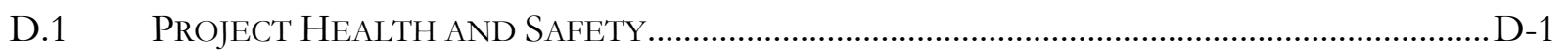

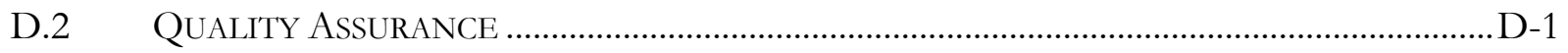

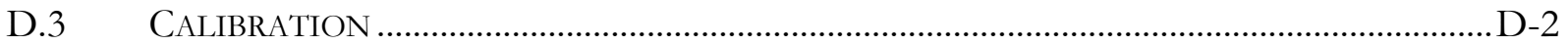




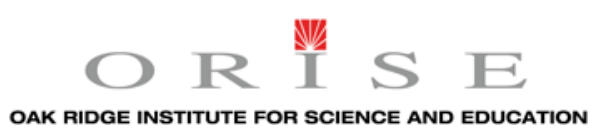

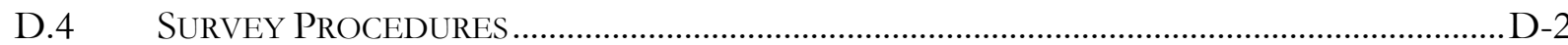

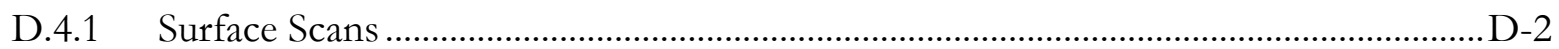

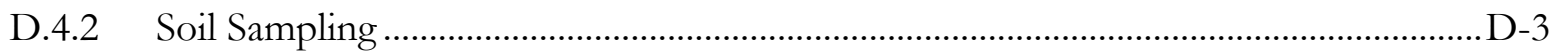

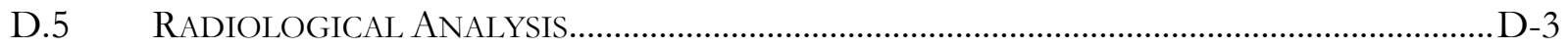

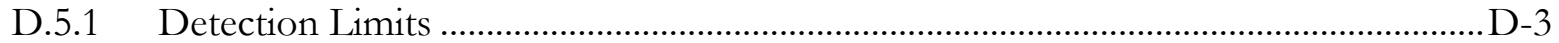

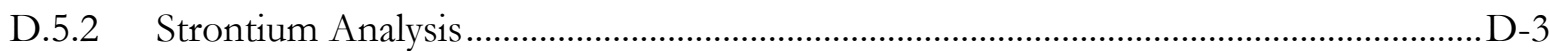

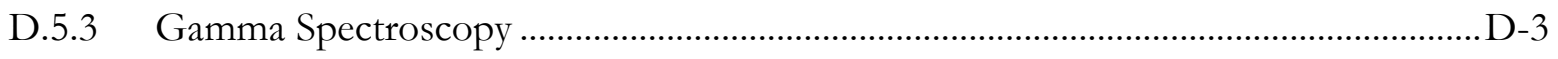

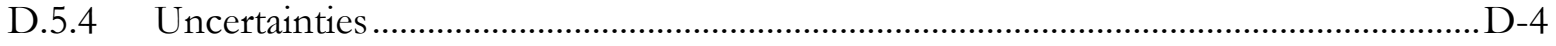




\section{LIST OF FIGURES}

Figure 1: LISF Survey Unit Ranked Set Sampling-Cycle, Sets, and Locations ......................................5

Figure A-1: Location of Brookhaven National Laboratory, Upton, New York ................................ A-1

Figure A-2: Plot Plan of the Long Island Solar Farm ........................................................................... A-2

Figure A-3: Long Island Solar Farm Gamma Scan Survey .................................................................. A-3

Figure A-4: Long Island Solar Farm Ranked Set Sampling Locations ............................................... A-4

Figure A-5: Long Island Solar Farm Soil Sample Locations .................................................................... A-5

Figure A-6: Verification Gamma Scan Count Rate Histogram (Normalized Data) ........................... A-6 


\section{LIST OF TABLES}

Table 1: Radionuclides of Concern in the Long Island Solar Farm ..................................................6

Table B-1: Ranked Set Sampling Gamma Measurements.....................................................................-1

Table B-2: Radionuclide Concentrations In Soil.................................................................................... 


\section{ABBREVIATIONS AND ACRONYMS}

\begin{tabular}{|c|c|}
\hline AEC & Atomic Energy Commission \\
\hline $\mathrm{AOC}$ & area of concern \\
\hline $\mathrm{BKG}$ & background \\
\hline BHSO & Brookhaven Site Office \\
\hline BNL & Brookhaven National Laboratory \\
\hline $\begin{array}{l}\text { CERCLA } \\
\mathrm{cm}\end{array}$ & $\begin{array}{l}\text { Comprehensive Environmental Response, Compensation, and Liability Act } \\
\text { centimeter }\end{array}$ \\
\hline $\mathrm{cpm}$ & counts per minute \\
\hline $\mathrm{DCGL}_{\mathrm{W}}$ & derived concentration guideline level \\
\hline DOE & U.S. Department of Energy \\
\hline EPA & Environmental Protection Agency \\
\hline FIPS & Federal Information Processing Standard \\
\hline FHWMF & Former Hazardous Waste Management Facility \\
\hline FSP & Field Sampling Plan \\
\hline FSS & final status survey \\
\hline GPS & global positioning system \\
\hline HFBR & High Flux Beam Reactor \\
\hline ISM & Integrated Safety Management \\
\hline ITP & Intercomparison Testing Program \\
\hline IV & independent verification \\
\hline JHA & job hazard analysis \\
\hline LIPA & Long Island Power Authority \\
\hline LISF & Long Island Solar Farm \\
\hline MAPEP & Mixed Analyte Performance Evaluation Program \\
\hline MARSSIM & Multi-Agency Radiation Survey and Site Investigation Manual \\
\hline MDC & minimum detectable concentration \\
\hline $\mathrm{MeV}$ & million electron volts \\
\hline $\mathrm{m}^{2}$ & square meter \\
\hline $\mathrm{NaI}$ & sodium iodide \\
\hline NIST & National Institute of Standards and Technology \\
\hline NRIP & NIST Radiochemistry Intercomparison Program \\
\hline ORAU & Oak Ridge Associated Universities \\
\hline ORISE & Oak Ridge Institute for Science and Education \\
\hline OU & Operable Unit \\
\hline $\mathrm{pCi} / \mathrm{g}$ & picocuries per gram \\
\hline PSP & project-specific plan \\
\hline RCRA & Resource Conservation and Recovery Act \\
\hline RSS & ranked set sampling \\
\hline SPCS & State Plane Coordinate System \\
\hline SU & survey unit \\
\hline TAP & total absorption peak \\
\hline VSP & Visual Sampling Plan \\
\hline
\end{tabular}




\section{INDEPENDENT VERIFICATION SURVEY REPORT FOR THE LONG ISLAND SOLAR FARM BROOKHAVEN NATIONAL LABORATORY UPTON, NEW YORK}

\subsection{INTRODUCTION}

The Brookhaven National Laboratory (BNL) located in Upton, Suffolk County, New York conducts research and development for the U.S. Department of Energy (DOE) Figure A-1. The BNL site was originally occupied by the U.S. Army as Camp Upton during both World Wars I and II. In 1947, the site was transferred to the Atomic Energy Commission (AEC). The AEC was resolved into the Energy Research and Development Administration, and later into the U.S. Department of Energy.

On December 21, 1989, BNL was included on the Comprehensive Environmental Response, Compensation, and Liability Act (CERCLA) National Priority List. The DOE-Brookhaven Site Office (BHSO) entered into an agreement to establish the framework and schedule for characterizing, assessing, and remediating the site in accordance with CERCLA and the Resource Conservation and Recovery Act (RCRA) requirements. BNL generated the Response Strategy Document that identified various Areas of Concern (AOC) and grouped each AOC into seven “Operable Units" (OU). OU-1 is the Former Hazardous Waste Management Facility (FHWMF); and just to the south is an 11-acre site that DOE will provide as an easement to the Long Island Power Authority (LIPA) to establish and operate the Long Island Solar Farm (LISF): a large-scale solar energy facility.

The LISF will eventually have the capacity to generate up to 32MW of power to LIPA consumers. At its peak capacity, the LISF will utilize at least 200 acres of BNL unused land resources. During the initial start-up, the LISF project will install ground mounted crystalline solar photovoltaic modules in an area of 11 acres just east of the FHWMF (BNL 2010).

DOE-BHSO is responsible for oversight of remedial actions that are conducted at the BNL. It is the policy of the DOE to perform independent (third party) verification of final status survey (FSS) activities (DOE 2006). The purpose of independent verification (IV) is to confirm that remedial actions have been effective in meeting established guidelines and that documentation accurately and adequately describes the final site conditions. Oak Ridge Institute for Science and Education (ORISE) has been requested by DOE-BHSO to perform IV of the LISF. Through a third party, 
DOE can provide a level of assurance to the stakeholders that the as-left radiological concentration in the LISF will be well below the approved remediation guidelines.

ORISE conducted IV of accessible areas to confirm that the FSS sampling results could be independently verified. ORISE implemented various survey activities that included walk-over gamma scans and soil sampling. The elements of the IV were based on the objectives specified in the project-specific plan (PSP) (ORISE 2010a).

The primary contaminants are cesium-137 and strontium-90. However, radium-226 has been identified at BNL in limited areas and in small quantities (Table 1).

\subsection{SITE DESCRIPTION}

The primary area of the LISF consists of 11 acres. The main section is located to the east of the FHWMF (Figure A-2). The smaller area is across Brookhaven Avenue on the north side of the road.

\subsection{OBJECTIVES}

The objective of the verification survey was to obtain evidence by means of measurements and sampling to confirm that the final radiological conditions were less than the cleanup goals. This objective was achieved via multiple verification components including document reviews to determine the accuracy and adequacy of FSS documentation.

\subsection{DOCUMENT REVIEW}

ORISE has reviewed various supporting documents for the LISF Project. Documents reviewed include the Addendum to the Field Sampling Plan (FSP) for the FHWMF, LISF Project Fact Sheet, and survey data results (BNL 2009 and 2010). The sample data were evaluated to assure that the residual activity levels in the soil satisfied the cleanup goals.

\subsection{PROCEDURES}

ORISE personnel visited the BNL site from September 25 through October 1, 2010, to perform visual inspections, independent measurements, and sampling. The verification activities were conducted in accordance with the project-specific verification plan and the IEAV Survey Procedures and Quality Program Manuals (ORISE 2010a and 2008, and ORAU 2009). The two verified site areas consisted of 11 acres divided by Brookhaven Avenue. Because the verified survey unit (SU) 
had the potential of being contaminated, it was designated as a Class 2 area in accordance with Multi-Agency Radiation Survey and Site Investigation Manual (MARSSIM) guidance (NRC 2000). From September 25 through 29, 2010, ORISE personnel performed medium-density walk-over surveys and conducted IV soil samples.

\subsection{REFERENCE SYSTEM}

ORISE used a global positioning system (GPS) for documenting survey area boundaries and tracking data. The specific geographic coordinate system used was the State Plane Coordinate System (SPCS) New York Long Island Federal Information Processing Standard (FIPS) 3104. A shape file of the area to be verified was not provided prior to verification survey activities. ORISE performed a walk-over survey with a GPS system along the boundary of the 11 acres to create the necessary shape file required to document scans and generate sample locations. Coordinate measurements collected using the GPS were accurate to within one meter.

\subsection{SURFACE SCANS}

Medium density surface scans for gamma radiation were conducted over the accessible Class 2 areas. Surface scans were performed using sodium iodide (NaI) scintillation detectors coupled to ratemeters or ratemeter-scalers with audible indicators. Detectors were coupled to GPS systems that enable real-time gamma count rate and position data capture (Figure A-3). Lead shields were inadvertently left on the detectors from previous IV survey activities around the High Flux Beam Reactor (HFBR). Upon discovery, this issue was immediately resolved by removing the shielding on the detectors in use. Scan surveys and direct measurement collection were finished using unshielded detectors. The data collected with the shielded detectors were normalized onsite to determine the correct locations to be sampled. The normalization method used is discussed in "Results and Findings.” Any locations of elevated direct radiation, exhibiting the presence of residual contamination, were to be marked and identified for further investigation.

\subsection{SOIL SAMPLING}

The Visual Sampling Plan (VSP) software was used to generate random coordinates for gamma measurements and soil sampling. These measurement/sample points were downloaded to the GPS and were based upon the reference grid system established for the site. The predetermined random 
field assessment and the resultant soil sample locations were designed and generated based on the ranked set sampling (RSS) approach (EPA 2006).

RSS provides a methodology to determine the necessary number of soil samples to estimate the mean concentration of a population; however, it does not require the assumption of a normal distribution. The process combines random sampling with the use of professional judgment to select sampling locations. Professional judgment relies upon the ability to assess the relative magnitude of gamma radiation levels between randomly selected locations. In this case, the gamma count rate data collected at randomly selected locations provided the measurable field screening method that correlates with the relative concentrations of the gamma-emitting contaminants of concern. The count rate data obtained were then used to select a specific sampling location.

VSP systematic planning process uses a replication method on a larger random population from which the locations for the resulting samples can be selected. Replication refers to the number of cycles $(r)$ for performing a set size $(m)$ of field measurement. The number of field assessment locations per cycle, is a function of the set size and is simply $m^{2}$. The total number of field assessment locations is then defined as $m^{2} \times r$ or in this example $3^{2} \times 3=27$. These measurements are grouped into cycle/sets and distributed in the survey area. The first location in cycle 1 of set 1 would be designated as 1-1-1. Mapping is color coded (based on cycle ID) using geometric shapes (based on set ID) to visually show the population of assessment locations. Specific measurement locations are generated via either a pseudo- or quasi-random approach. Figures 1 and A-4 represent the RSS measurement/sampling plan developed for use for the LISF. 


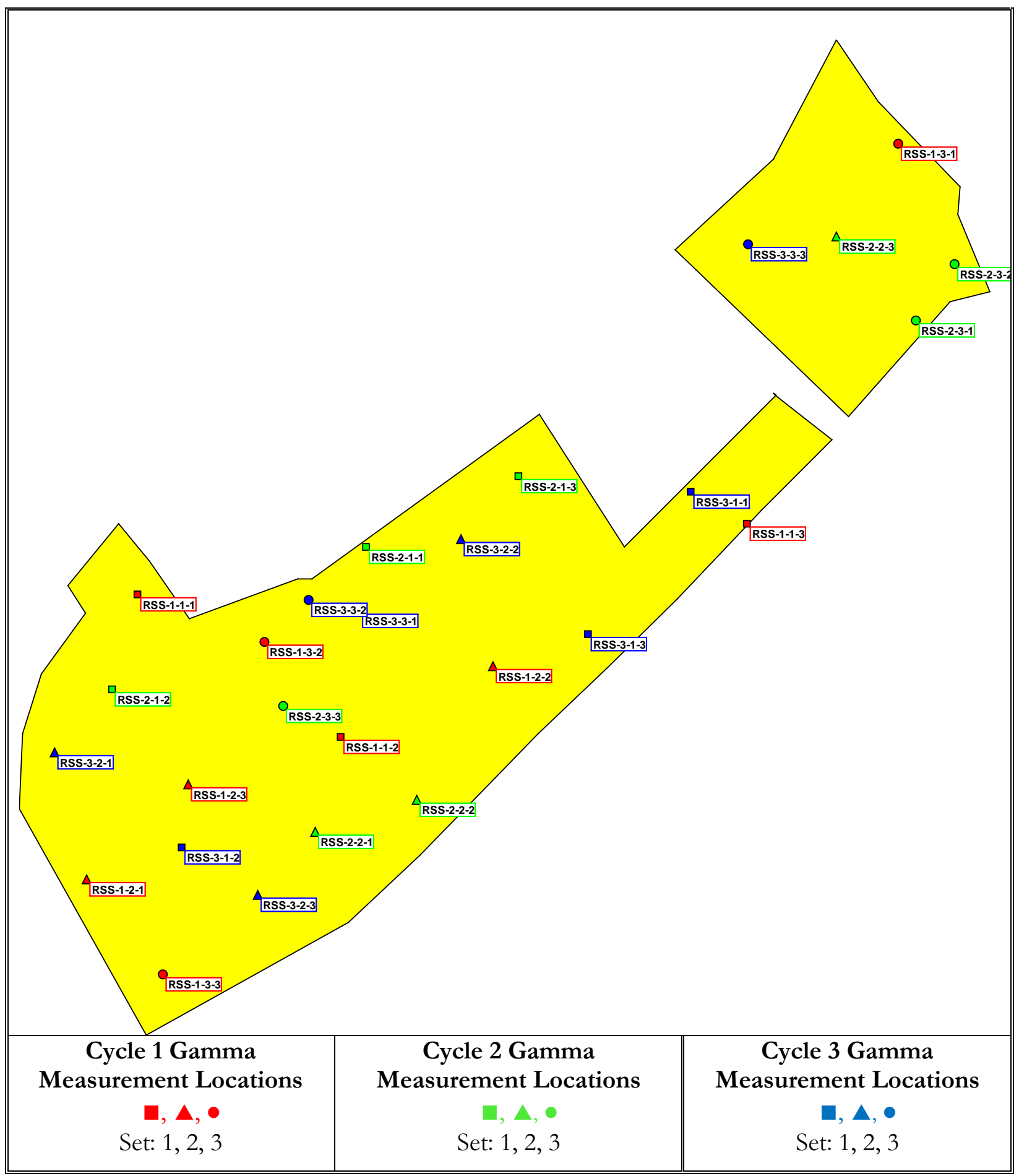

Figure 1: LISF Survey Unit Ranked Set Sampling-Cycle, Sets, and Locations

A one-minute static gamma count rate measurement was performed at each of the 27 assessment locations (Figures 1 and A-4). The data within a given cycle-set are then ranked as exhibiting either the lowest, medium, or highest gamma count. Nine soil samples were collected from the survey unit (Figure A-5). The following process was used to select the specific sampling location within each of 
the three cycles: Set 1, lowest gamma radiation location; Set 2, medium location; Set 3, highest location. Table B-1 provides the RSS cycle set with field assessment data and ranked set soil sample identification.

\subsection{SAMPLE ANALYSIS AND DATA INTERPRETATION}

Samples and data were returned to the ORISE laboratory in Oak Ridge, Tennessee for analysis and interpretation. Sample analyses were performed in accordance with the ORISE Laboratory Procedures Manual (ORISE 2010b). Soil samples were analyzed by gamma spectroscopy for radium-226 and cesium-137. The spectra were reviewed for other identifiable photopeaks. Strontium-90 was quantified by radiochemical separation and counting on a low background proportional counter. Soil sample results were reported in units of picocuries per gram (pCi/g) (Table B-2). The data generated were compared with the cleanup goals established for the LISF (BNL 2009).

\subsection{APPLICABLE SITE GUIDELINES}

The radiological contaminants of concern and the soil cleanup levels for the LISF are shown in Table 1 and have been previously identified in the FSP FHWMF Perimeter Area (BNL 2009). This FSP relies on the previously developed cleanup goals and derived concentration guideline levels $\left(\mathrm{DCGL}_{W}\right)$, because the LISF was originally a portion of the FHWMF Perimeter Area. Because multiple contaminants are present, application of the unity rule is involved requiring calculation of the sum-of-ratios in accordance with the following equation:

$$
\frac{\text { Conc. }_{R a-226}}{D C G L_{R a-226}}+\frac{\text { Conc }_{C_{S-137}}}{D C G L_{C s-137}}+\frac{\text { Conc }_{\text {Sr }^{-90}}}{D C G L_{S r-90}}+\leq 1
$$

\begin{tabular}{|c|c|}
\hline $\begin{array}{c}\text { TABLE 1: RADIONUCLIDES OF CONCERN IN THE } \\
\text { LONG ISLAND SOLAR FARM }\end{array}$ \\
BROOKHAVEN NATIONAL LABORATORY \\
\hline Radionuclide & LISF (pCi/g) \\
\hline Cs-137 & 23 \\
\hline Sr-90 & 15 \\
\hline Ra-226 & 5 \\
\hline
\end{tabular}




\subsection{FINDINGS AND RESULTS}

The results for each verification component at the LISF are discussed below.

\subsection{DOCUMENT REVIEW}

The supporting documents reviewed for the LISF Project included the scan survey data and limited gamma spectroscopy results. Complete FSS information and results were not available at the time of the verification survey. Due to incomplete FSS data results, ORISE increased the soil verification sample number to ensure adequate coverage for the LISF.

\subsection{SURFACE SCANS}

Gamma surface scan ranges for the LISF were typically 5,500 to 10,000 gross counts per minute (cpm) with a few small areas exhibiting counts up to approximately 18,000 cpm. As previously mentioned, shielded detectors were inadvertently used for the initial verification surveys of the LISF. The ratio of 1.55 was developed by re-establishing an unshielded background. The unshielded background average was divided by the average shielded background value. The 1.55 ratio was then applied to the data recorded with shielded detectors. The methodology for applying the 1.55 ratio to normalize the shielded measurement data was evaluated using Q-Q Plots generated in ProUCL Version 4.0 to verify the accuracy of the corrected background. The data in Table B-1 represents the normalized data collected during IV surveys.

Due to natural foliage and limited satellite reception, survey data for the gamma scan is sparsely represented in Figure A-3. A background reference area was not defined by ORISE prior to the survey; therefore, all point measurements contain gross data results. Figure A-6 provides a frequency histogram of the gamma scan count rate population.

\subsection{RADIONUCLIDE CONCENTRATIONS IN SOIL AND ROOF SAMPLES}

The gamma count rate data used for selecting the appropriate random sample locations can be found in Table B-1. The data for the radionuclide concentrations in individual samples are provided in Table B-2. The concentration of radium-226 in random samples ranged from 0.50 to $1.15 \mathrm{pCi} / \mathrm{g}$ and cesium-137 ranged from 0.22 to $1.27 \mathrm{pCi} / \mathrm{g}$. Strontium-90 results were considered to be in equilibrium and derived from the surrogate lead-214. Radionuclide concentration results for strontium-90 ranged from -0.11 to $0.19 \mathrm{pCi} / \mathrm{g}$. 


\subsection{COMPARISON OF RESULTS WITH GUIDELINES}

The final radionuclide concentration for the LISF meets the cleanup goals as described in the FSP. All values were less than the corresponding DCGL $\mathrm{L}_{\mathrm{W}}$. Soil sample concentrations were less than $25 \%$ of the respective DCGL $L_{\mathbb{W}}$ values for all radionuclides of concern.

\subsection{SUMMARY}

During the period between September 25 through 29, 2010, ORISE conducted independent measurements and sampling of the LISF on the BNL site. The portion of the LISF verified by this survey is an 11-acre area just east of the FHWMF that DOE will provide as an easement to the LIPA to establish and operate the LISF; a large-scale solar energy facility. It consists of a Class 2 survey unit divided into two parts (north and south) by Brookhaven Avenue. A majority of the scan results for the survey area were not distinguishable from background; and the elevated areas detected during IV surveys were investigated and determined to meet the cleanup goals. The results from soil sample analysis were less than $25 \%$ of respective DCGL $_{\mathbb{W}}$ for the radionuclides of concern. Verification survey activities validated the licensee's classifications, radiological status, and satisfaction of the guidelines. 


\subsection{REFERENCES}

Brookhaven National Laboratory (BNL). "Addendum to Field Sampling Plan for Former Hazardous Waste Management Facility Perimeter Area.” Upton, New York; September 8, 2010.

BNL. "Field Sampling Plan for Former Hazardous Waste Management Facility Perimeter Area." Upton, New York; August 19, 2009.

Oak Ridge Associated Universities (ORAU). "Quality Program Manual for the Independent Environmental Assessment and Verification Program.” Oak Ridge, Tennessee; June 30, 2009.

Oak Ridge Institute for Science and Education (ORISE). "Project-Specific Verification Plan for the Long Island Solar Farm at the Brookhaven National Laboratory.” Upton, New York. Oak Ridge, Tennessee; October 11, 2010a.

ORISE. "Laboratory Procedures Manual for the Environmental Survey and Site Assessment Program.” Oak Ridge, Tennessee; October 8, 2010 b.

ORISE. "Survey Procedures Manual for the Independent Environmental Assessment and Verification Program.” Oak Ridge, Tennessee; May 1, 2008.

U.S. Department of Energy (DOE). "Environment, Safety, and Health Bulletin: A Guide to Good Practices for the Control and Release of Property." DOE/EH-0697. Washington, D.C.; July 2006.

U.S. Environmental Protection Agency (EPA). "Data Quality Assessment: Statistical Methods for Practitioners.” EPA QA/G-9S; Washington, D.C.; February 2006.

U.S. Nuclear Regulatory Commission (NRC). "Multi-Agency Radiation Survey and Site Investigation Manual (MARSSIM), NUREG-1575”; Revision 1; Washington, DC; August 2000. 
APPENDIX A FIGURES 


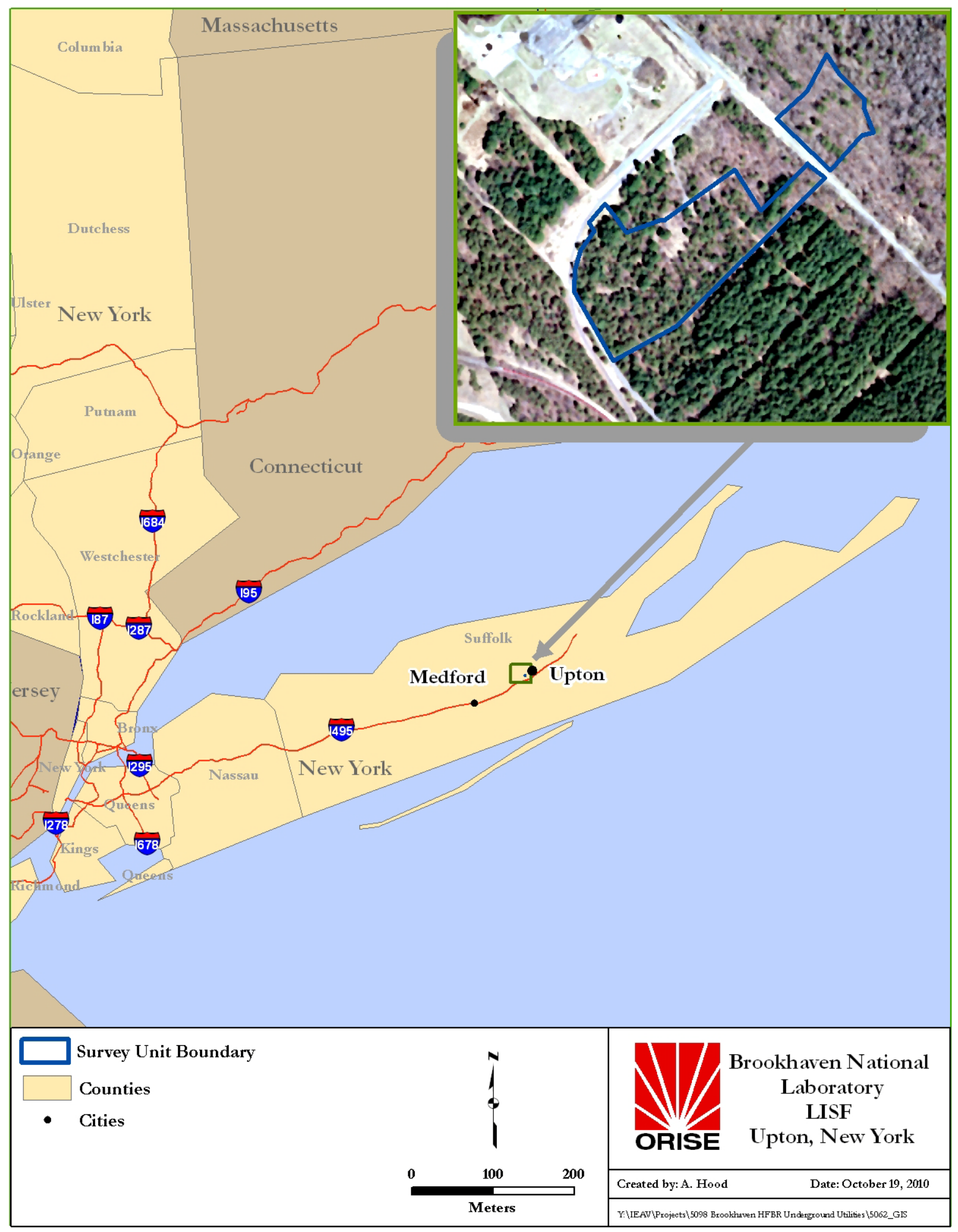

Figure A-1: Location of Brookhaven National Laboratory, Upton, New York 


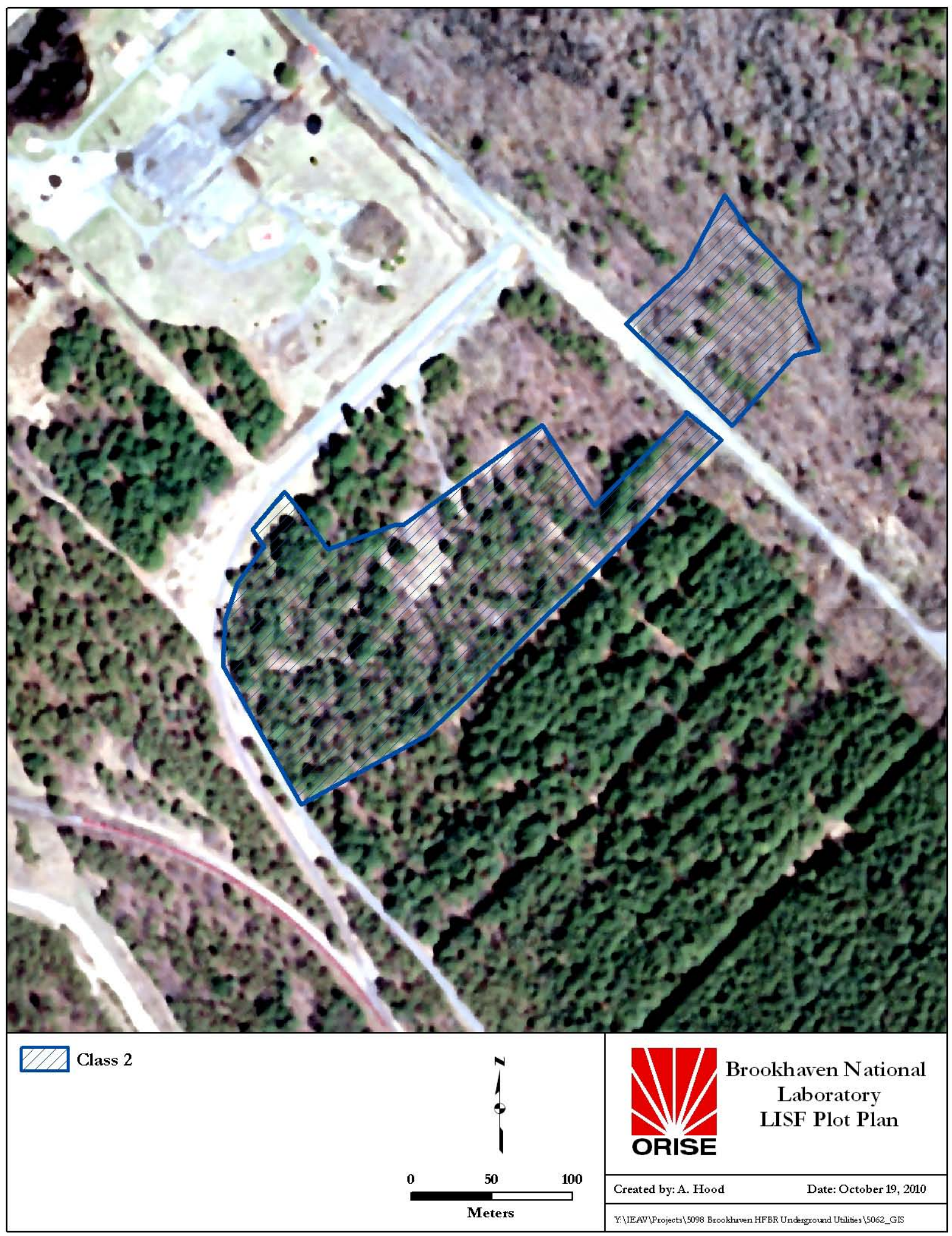

Figure A-2: Plot Plan of the Long Island Solar Farm 


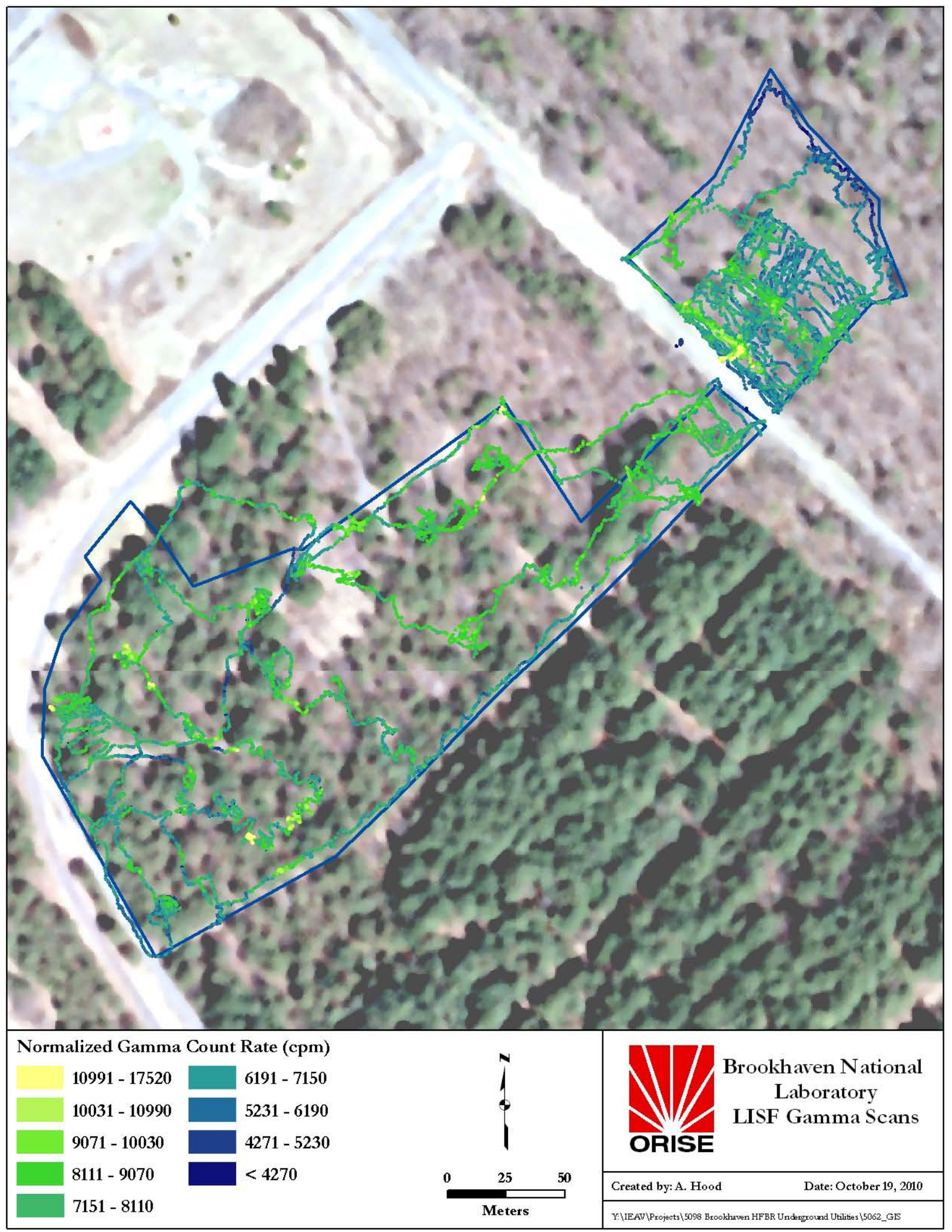

Figure A-3: Long Island Solar Farm Gamma Scan Survey 


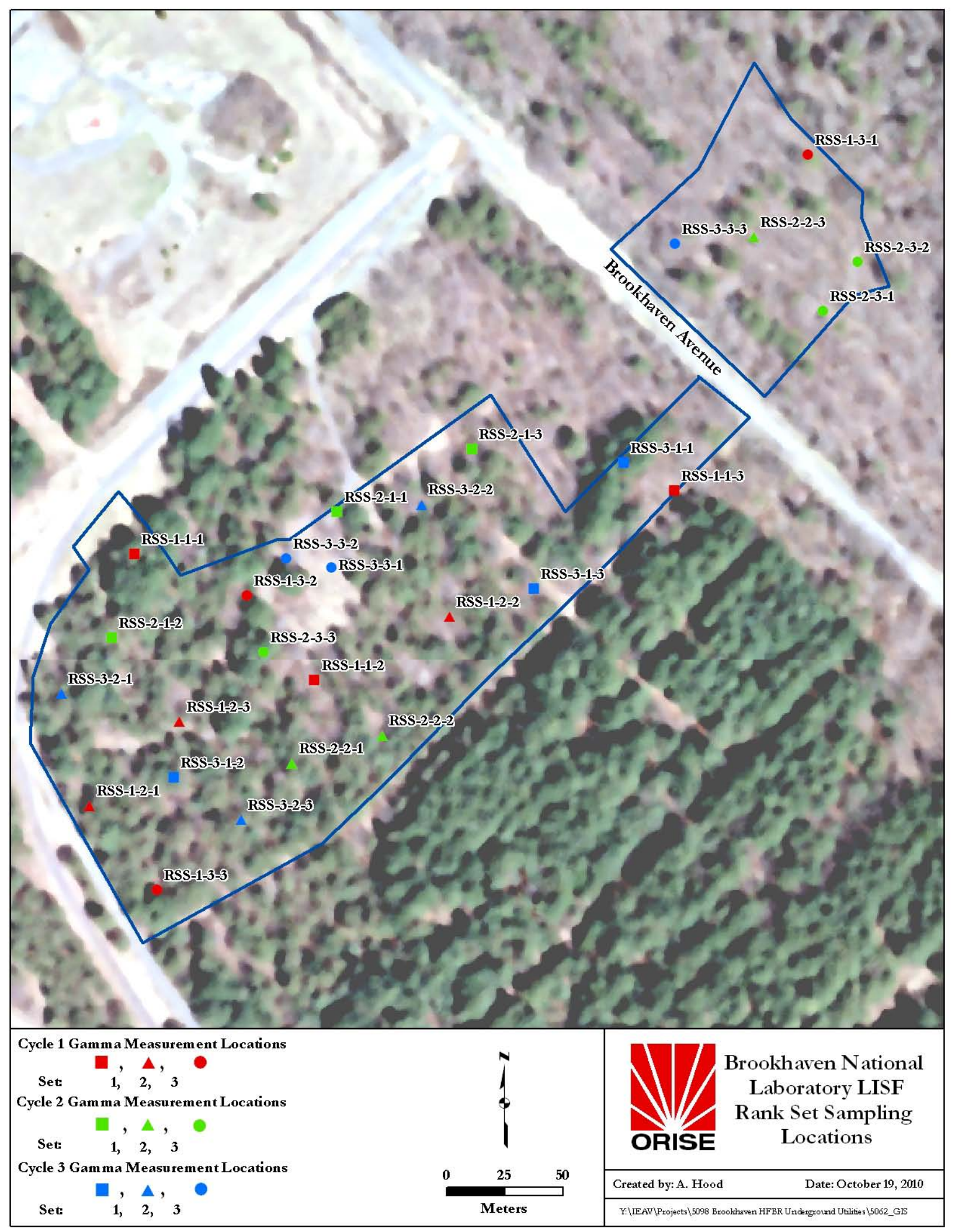

Figure A-4: Long Island Solar Farm Ranked Set Sampling Locations 


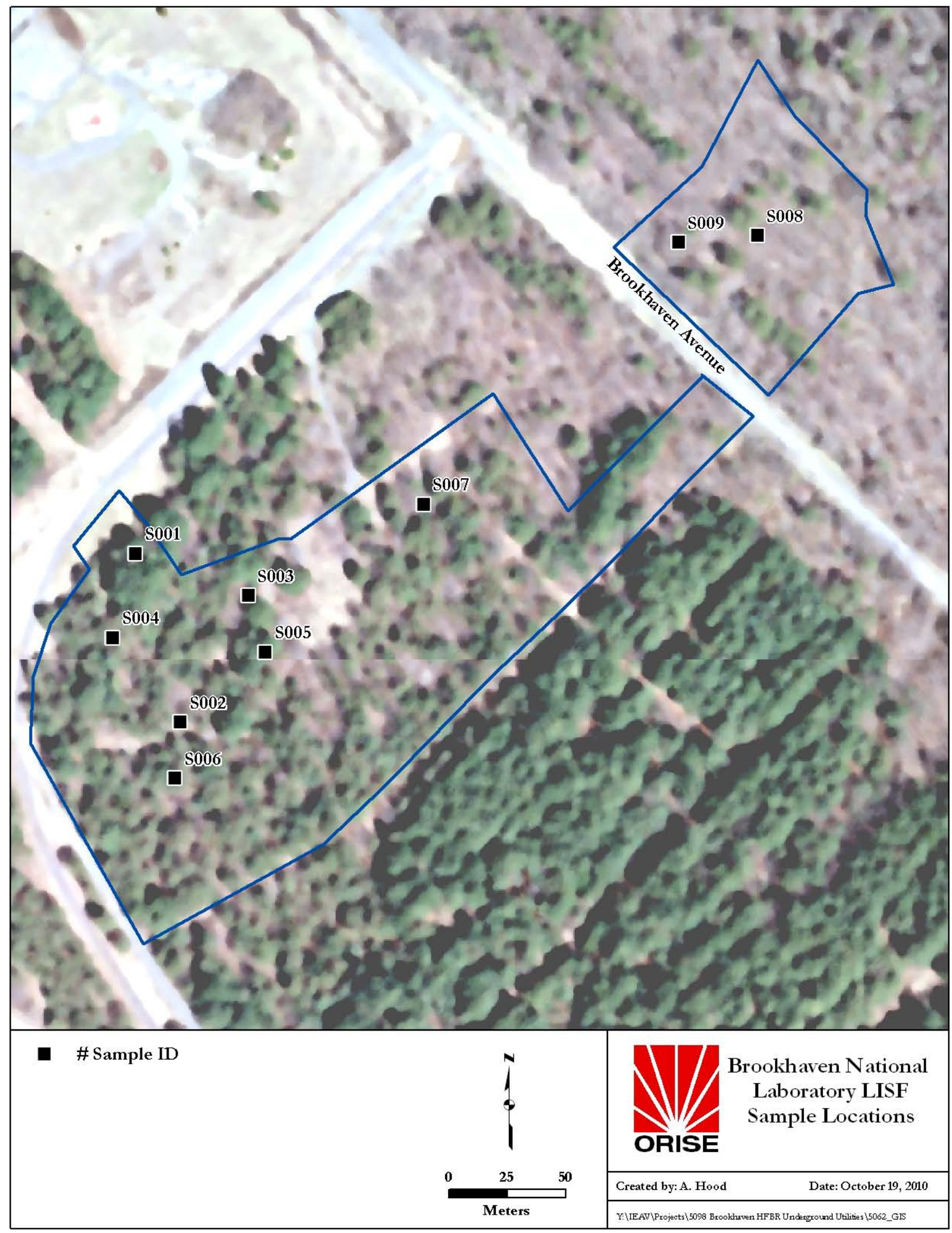

Figure A-5: Long Island Solar Farm Soil Sample Locations 


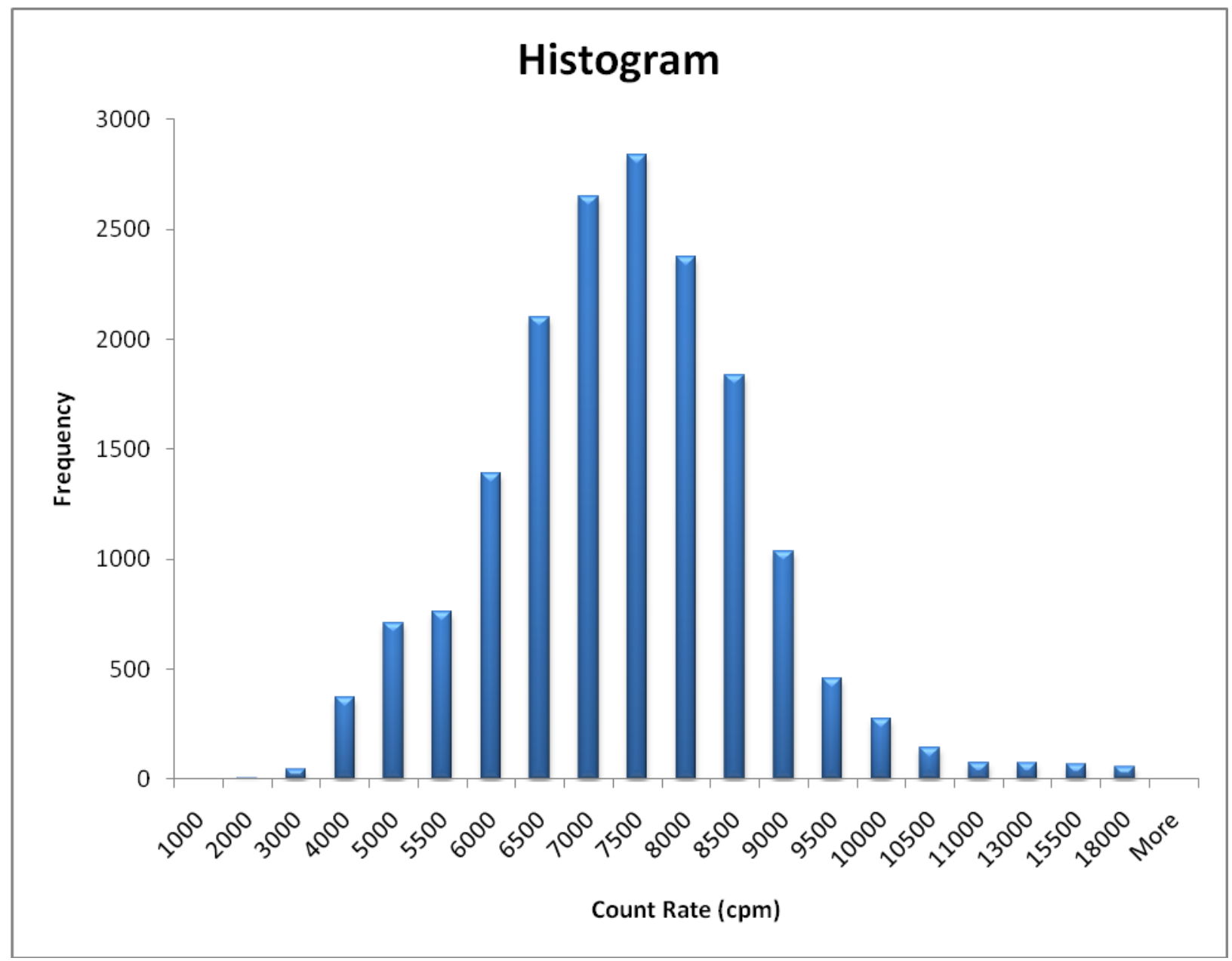

Figure A-6: Verification Gamma Scan Count Rate Histogram (Normalized Data) 
APPENDIX B

TABLES 


\begin{tabular}{|c|c|c|c|c|c|c|c|c|c|}
\hline \multicolumn{10}{|c|}{$\begin{array}{c}\text { TABLE B-1: RANKED SET SAMPLING GAMMA MEASUREMENTS } \\
\text { LONG ISLAND SOLAR FARM } \\
\text { BROOKHAVEN NATIONAL LABORATORY } \\
\text { UPTON, NEW YORK }\end{array}$} \\
\hline \multirow{2}{*}{$\begin{array}{l}\text { Northing } \\
\text { (m) }\end{array}$} & \multirow{2}{*}{$\begin{array}{l}\text { Easting } \\
\text { (m) }\end{array}$} & \multicolumn{4}{|c|}{$\begin{array}{l}\text { RSS Measurement } \\
\text { Location }^{\mathrm{a}}\end{array}$} & \multirow{2}{*}{$\begin{array}{c}\text { Gamma } \\
\text { Count } \\
(\mathrm{c} / \mathrm{m})\end{array}$} & \multirow{2}{*}{ Value } & \multirow{2}{*}{$\begin{array}{c}\text { Soil } \\
\text { Sample \# }\end{array}$} & \multirow{2}{*}{$\begin{array}{l}\text { Soil Gamma } \\
\text { Count }(\mathrm{cpm})\end{array}$} \\
\hline & & Cycle & Set & \# & Symbol & & & & \\
\hline 254148 & 1299955 & 1 & 1 & 1 & $\square$ & $6995^{b}$ & $\mathrm{~L}$ & 5119S0001 & 8714 \\
\hline 253971 & 1300209 & 1 & 1 & 2 & $\mathbf{\square}$ & $7930^{\mathrm{b}}$ & & & \\
\hline 254237 & 1300715 & 1 & 1 & 3 & 口 & 7943 & & & \\
\hline 253793 & 1299892 & 1 & 2 & 1 & $\Delta$ & $6484^{b}$ & & & \\
\hline 254060 & 1300399 & 1 & 2 & 2 & $\Delta$ & 8352 & & & \\
\hline 253912 & 1300019 & 1 & 2 & 3 & $\Delta$ & $7511^{\mathrm{b}}$ & M & $5119 S 0002$ & 9195 \\
\hline 254710 & 1300903 & 1 & 3 & 1 & ○ & 4980 & & & \\
\hline 254089 & 1300114 & 1 & 3 & 2 & 0 & $7638^{\mathrm{b}}$ & $\mathrm{H}$ & $5119 S 0003$ & 9711 \\
\hline 253675 & 1299987 & 1 & 3 & 3 & ○ & $7175^{\mathrm{b}}$ & & & \\
\hline 254208 & 1300240 & 2 & 1 & 1 & $\square$ & 8512 & & & \\
\hline 254030 & 1299924 & 2 & 1 & 2 & $\square$ & $7432^{\mathrm{b}}$ & $\mathrm{L}$ & $5119 S 0004$ & 10451 \\
\hline 254296 & 1300430 & 2 & 1 & 3 & $\square$ & 8020 & & & \\
\hline 253853 & 1300177 & 2 & 2 & 1 & $\Delta$ & $6229^{b}$ & & & \\
\hline 253892 & 1300304 & 2 & 2 & 2 & $\Delta$ & $6964^{b}$ & & & \\
\hline 254595 & 1300827 & 2 & 2 & 3 & $\Delta$ & 6843 & $\mathrm{M}$ & $5119 S 0005$ & 7708 \\
\hline 254490 & 1300925 & 2 & 3 & 1 & 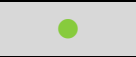 & 7035 & & & \\
\hline 254560 & 1300974 & 2 & 3 & 2 & \% & 6251 & & & \\
\hline 254010 & 1300137 & 2 & 3 & 3 & O & $7398^{b}$ & $\mathrm{H}$ & $5119 S 0006$ & 6403 \\
\hline 254277 & 1300644 & 3 & 1 & 1 & $\square$ & 7972 & & & \\
\hline 253833 & 1300011 & 3 & 1 & 2 & $\square$ & $6905^{b}$ & $\mathrm{~L}$ & $5119 S 0007$ & 9280 \\
\hline 254099 & 1300517 & 3 & 1 & 3 & $\square$ & 8416 & & & \\
\hline 253951 & 1299852 & 3 & 2 & 1 & $\Delta$ & $8341^{b}$ & & & \\
\hline 254217 & 1300359 & 3 & 2 & 2 & $\Delta$ & 7796 & M & $5119 S 0008$ & 8751 \\
\hline 253774 & 1300106 & 3 & 2 & 3 & $\Delta$ & $7394^{b}$ & & & \\
\hline 254129 & 1300232 & 3 & 3 & 1 & 0 & 7577 & & & \\
\hline 254142 & 1300169 & 3 & 3 & 2 & 0 & 7814 & & & \\
\hline 254585 & 1300716 & 3 & 3 & 3 & - & 8218 & $\mathrm{H}$ & 5119S0009 & 9606 \\
\hline
\end{tabular}

aRefer to Figure A-4.

${ }^{b}$ Gross counts were normalized to unshielded measurements by applying a multiplication factor of 1.55 to the shielded measurement result. 


\begin{tabular}{|c|c|c|c|c|}
\hline \multirow{3}{*}{ ORISE Sample ID ${ }^{a}$} & \multicolumn{3}{|c|}{$\begin{array}{l}\text { LONG ISLAND SOLAR FARM } \\
\text { ROOKHAVEN NATIONAL LABORATORY } \\
\text { UPTON, NEW YORK }\end{array}$} & \\
\hline & \multicolumn{4}{|c|}{ Radionuclide Concentration (pCi/g) } \\
\hline & Ra-226 & Cs-137 & Sr-90 & Sum of Ratios \\
\hline $5119 S 0001$ & $0.54 \pm 0.06^{\mathrm{b}}$ & $0.97 \pm 0.09$ & $0.40 \pm 0.44$ & 0.18 \\
\hline $5119 S 0002$ & $0.79 \pm 0.08$ & $0.65 \pm 0.08$ & $-0.11 \pm 0.47$ & 0.18 \\
\hline $5119 S 0003$ & $0.80 \pm 0.07$ & $0.44 \pm 0.05$ & $0.04 \pm 0.47$ & 0.18 \\
\hline $5119 S 0004$ & $1.15 \pm 0.10$ & $0.69 \pm 0.08$ & $-0.09 \pm 0.46$ & 0.25 \\
\hline $5119 S 0005$ & $0.50 \pm 0.07$ & $1.27 \pm 0.12$ & $0.19 \pm 0.44$ & 0.17 \\
\hline $5119 S 0006$ & $0.61 \pm 0.07$ & $1.19 \pm 0.13$ & $0.12 \pm 0.46$ & 0.18 \\
\hline $5119 S 0007$ & $0.68 \pm 0.07$ & $0.98 \pm 0.10$ & $0.10 \pm 0.41$ & 0.19 \\
\hline $5119 S 0008$ & $0.54 \pm 0.06$ & $0.22 \pm 0.04$ & $-0.05 \pm 0.41$ & 0.11 \\
\hline $5119 \$ 0009$ & $0.65 \pm 0.08$ & $1.01 \pm 0.10$ & $0.07 \pm 0.43$ & 0.18 \\
\hline
\end{tabular}

aRefer to Figure A-5.

bUncertainties represent the $95 \%$ confidence level based on total propagated uncertainties. 


\section{APPENDIX C MAJOR INSTRUMENTATION}


The display of a specific product is not to be construed as an endorsement of the product or its manufacturer by the author or his employer.

\section{C.1 SCANNING AND MEASUREMENT InStrument/DeteCtor Combinations}

Ludlum NaI Scintillation Detector Model 44-10, Crystal: 2 inch x 2 inch

(Ludlum Measurements, Inc., Sweetwater, TX)

Coupled to

Ludlum Ratemeter-Scaler Model 2221

Coupled to

Trimble GeoXH Receiver and Data Logger (Trimble Navigation Limited, Sunnyvale, CA)

\section{C.2 LABORATORY ANALYTICAL INSTRUMENTATION}

High-Purity Extended Range Intrinsic Detector

CANBERRA/Tennelec Model No: ERVDS30-25195

(Canberra, Meriden, CT)

Used in conjunction with:

Lead Shield Model G-11

(Nuclear Lead, Oak Ridge, TN)

Multichannel Analyzer

Dell Workstation and Canberra's Apex

Gamma Software (Canberra, Meriden, CT)

High-Purity Extended Range Intrinsic Detector

Model No. GMX-45200-5

(AMETEK/ORTEC, Oak Ridge, TN)

used in conjunction with:

Lead Shield Model SPG-16-K8

(Nuclear Data)

Multichannel Analyzer

Dell Workstation and Canberra's Apex

Gamma Software (Canberra, Meriden, CT)

High-Purity Germanium Detector

Model GMX-30-P4, 30\% Eff.

(AMETEK/ORTEC, Oak Ridge, TN)

Used in conjunction with:

Lead Shield Model G-16

(Gamma Products, Palos Hills, IL)

and Multichannel Analyzer

Dell Workstation and Canberra's Apex

Gamma Software (Canberra, Meriden, CT) 
APPENDIX D

SURVEY AND ANALYTICAL PROCEDURES 


\section{D.1 Project Health AND SAFETy}

The survey and sampling procedures were evaluated to ensure that any hazards inherent to the procedures themselves were addressed in current job hazard analyses (JHAs). All survey and laboratory activities were conducted in accordance with ORISE health and safety and radiation protection procedures.

Presurvey activities included an overview of potential health and safety issues. Representatives with the BNL provided site-specific safety awareness training for each individual ORISE survey effort. In-process and verification surveys were performed according to the ORISE generic health and safety plan, site-specific Integrated Safety Management (ISM) prejob hazard checklist, and safety procedures discussed during the on-site training.

\section{D.2 Quality AssurancE}

Analytical and field survey activities were conducted in accordance with procedures from the following ORAU and ORISE documents:

- Survey Procedures Manual

- Laboratory Procedures Manual

- Quality Program Manual

The procedures contained in these manuals were developed to meet the requirements of 10 CFR 830 Subpart A, Quality Assurance Requirements, Department of Energy Order 414.1C, Quality Assurance, and the U.S. Nuclear Regulatory Commission, Quality Assurance Manual for the Office of Nuclear Material Safety and Safeguards, and contain measures to assess processes during their performance.

Quality control procedures include:

- Daily instrument background and check-source measurements to confirm that equipment operation is within acceptable statistical fluctuations.

- Participation in Mixed Analyte Performance Evaluation Program (MAPEP), National Institute for Standards and Technology (NIST) Radiochemistry Intercomparison 
Program (NRIP), and Intercomparison Testing Program (ITP) Laboratory Quality Assurance Programs.

- Training and certification of all individuals performing procedures.

- Periodic internal and external audits.

\section{D.3 CALIBration}

Calibration of all field and laboratory instrumentation was based on standards/sources, traceable to NIST, when such standards/sources were available. In cases where they were not available, standards of an industry-recognized organization were used.

\section{D.4 Survey Procedures}

\section{D.4.1 Surface Scans}

Scans for elevated gamma radiation were performed by passing the detector slowly over the surface. The distance between the detector and surface was maintained at a nominal of about 1 to 5 centimeter $(\mathrm{cm})$. NaI scintillation detectors were coupled to GPS units that enabled real-time recording of position in one-second intervals. Identification of elevated radiation levels was based on increases in the audible signal from the instrument. Positioning data files were downloaded from field data loggers for plotting using commercially available software (http://trl.trimble.com/docushare/dsweb/Get/Document-261826/GeoExpl2005 100A GSG ENG.pdf).

The scan minimum detectable concentrations (MDCs) for the $\mathrm{NaI}$ scintillation detector for the contaminants of concern in surface soil were obtained directly from NUREG- $1507^{1}$ when available or estimated using the calculation approach described in NUREG-1507. A typical NaI 2-inch by 2-inch detector MDC for Cs-137 is $6.4 \mathrm{pCi} / \mathrm{g}$. An audible increase in the activity rate was investigated by ORISE. It is standard procedure for ORISE staff to pause and investigate any locations where gamma radiation is distinguishable from background levels.

${ }^{1}$ NUREG-1507. Minimum Detectable Concentrations With Typical Radiation Survey Instruments for Various Contaminants and Field Conditions. U.S. Nuclear Regulatory Commission. Washington, DC; June 1998. 


\section{D.4.2 Soil Sampling}

Approximately 0.5 to 1 kilogram of soil was collected at each sample location. Collected samples were placed in plastic bags, sealed, and labeled in accordance with ORISE survey procedures.

\section{D.5 Radiological ANALysis}

\section{D.5.1 Detection Limits}

Detection limits, referred to as MDC, were based on 3 plus 4.65 times the standard deviation of the background count $\left[3+\left(4.65(\mathrm{BKG})^{1 / 2}\right)\right]$. Because of variations in background levels, measurement efficiencies, and contributions from other radionuclides in samples, the detection limits differ from sample to sample and instrument to instrument.

\section{D.5.2 Strontium Analysis}

Soil samples were dissolved by a combination of potassium hydrogen fluoride and pyrosulfate fusions. The fusion cake was dissolved and strontium was coprecipitated on lead sulfate. The strontium was separated from residual calcium and lead by reprecipitating strontium sulfate from EDTA at a $\mathrm{pH}$ of 4.0. Strontium was separated from barium by complexing the strontium in DTPA while precipitating barium as barium chromate. The strontium was ultimately converted to strontium carbonate and counted on a low-background gas proportional counter. The typical MDC of the procedure is $0.4 \mathrm{pCi} / \mathrm{g}$ for a one hour count time.

\section{D.5.3 Gamma Spectroscopy}

Samples of soil were dried, mixed, crushed, and/or homogenized as necessary, and a portion sealed in a 0.5 -liter Marinelli beaker or other appropriate container. The quantity placed in the beaker was chosen to reproduce the calibrated counting geometry. Net material weights were determined and the samples counted using intrinsic germanium detectors coupled to a pulse height analyzer system. Background and Compton stripping, peak search, peak identification, and concentration calculations were performed using the computer capabilities inherent in the analyzer system. All total absorption peaks (TAP) associated with the radionuclides of concern were reviewed for consistency of activity. Total absorption peaks used for determining the activities of radionuclides of concern and the typical associated MDCs for a one-hour count time were: 


\begin{tabular}{|c|c|c|}
\hline Radionuclide & TAP $(\mathbf{M e V})$ & MDC $(\mathbf{p C i} / \mathbf{g})$ \\
\hline Ra-226 (from Pb-214) & 0.351 & 0.08 \\
\hline Cs-137 & 0.662 & 0.05 \\
\hline Sr-90 & NA & 0.40 \\
\hline
\end{tabular}

Spectra were also reviewed for other identifiable TAPs.

\section{D.5.4 Uncertainties}

The uncertainties associated with the analytical data presented in the tables of this report represent the total propagated uncertainties for those data. These uncertainties were calculated based on both the gross sample count levels and the associated background count level. 